\title{
OS EFEITOS DO BINARISMO DE GÊNERO NAS ESTRUTURAS COGNITIVASE NA CONSTRUÇÃO DO PENSAMENTO SOCIAL DOS FLLHOS DA INJÚRIA
}

\author{
THE EFFECTS OF GENDER BINARISM IN COGNITIVE STRUCTURES AND SOCIAL CONSTRUCTION THOUGHT \\ OF INJURY'S CHILDREN
}

\section{RESUMO}

Este trabalho teve como objetivo investigar as representações sociais de masculinidades e amor para travestis, homens gays e homens heterossexuais. Utilizamos um questionário com questões abertas e fechadas distribuídas em três blocos temáticos: (1) ser homem, ser mulher; (2) amor e sexo; (3) preconceito e homofobia. Participaram 131 pessoas, divididas em três grupos: 40 homens heterossexuais, 52 homens gays e 39 travestis. Para análise dos dados utilizamos o software ALCESTE, ferramenta comumente utilizada em estudos sobre representações sociais. As representações sociais de masculinidades possuem elementos que ora aproximam, ora distanciam dos grupos trabalhados. $\mathrm{O}$ amor, objeto investigado, atua na constituição das identidades de gêneros dos três grupos revelando práticas que reforçam os binarismos de gênero. Já os discursos que justificam o preconceito e a discriminação, vivenciados ou não, assentam-se sobre as estruturas cognitivas dos grupos pesquisados conferindo legitimidade a estas mesmas identidades grupais e respectivas práticas.

Palavras-chave: Masculinidades. Representações Sociais. Travestis. Gays.

\begin{abstract}
The objective of this work was to investigate the social male representation and love for transvestites, gay men, and heterosexual men. We used a questionnaire with open and closed questions distributed among three thematic groups: (1) Being a man, (2) being a woman; (3) love and sex; (4) prejudice and homophobia. 131 people participated, they were divided into three groups: 40 heterosexual men, 52 gay men, and 39 transvestites. We used the ALCEST software to analyze the data, a tool frequently used in studies on social representations. The social male representation contains elements which sometimes approach and sometimes are away from the workgroups. Love, the investigated object, acts in the constitution of the gender identities of the three groups revealing practices that reinforce gender binarism. the

Rebeca V. Bussinger

Professora Adjunto A - Universidade Federal do Sul da Bahia (UFSB) - BA/ Brasil. Doutora em Psicologia pela Universidade Federal do Espírito Santo (UFES). Graduação em Psicologia, mestrado e doutorado em Psicologia Social. E-mail: rebecabussinger@hotmail.com

Maria Cristina S. Menandro

Professora Doutora do Programa de Pós-Graduação em Psicologia da Universidade Federal do Espírito Santo (UFES) - ES/Brasil. Graduação em Psicologia, mestrado e doutorado em Psicologia Social. E-mail: cristinasmithmenandro@gmail.com
\end{abstract}


discourses that justify prejudice and discrimination, whether lived or not, are based on the cognitive structures of the researched groups, conferring legitimacy to these same group identities and respective practices.

Keywords: Masculinities. Social Representations. Transvestites. Gays.

\section{Introdução}

O Brasil e o mundo vivem atualmente uma ofensiva antigênero. Associada a governos que ascendem ao poder por pautas consideradas conservadoras, iniciou-se uma caça às bruxas a pesquisadoras/es, ativistas e militantes defensores de Direitos Humanos, especialmente das causas LGBTI ${ }^{1}$. Na América Latina e no Brasil de 2019, o combate à "ideologia de gênero" tem como retórica destes acontecimentos a exacerbação de uma "Teologia de Estado", termo que usamos para expressar o apelo que tais discursos populistas utilizam para supor a ideia de retomada da ordem social em contextos de inúmeras complexidades sociais, culturais e econômicas.

Este artigo retoma dados de uma pesquisa de doutorado que foi realizada em três etapas. $\mathrm{O}$ foco apresentado aqui teve como principal objetivo investigar as representações sociais de masculinidades e amor de homens gays, heterossexuais e travestis. Neste momento, pensamos ser importante contribuir com o campo teórico e científico dos debates de gêneros e sexualidades, considerando produtivas as divergências heurísticas deste campo, sem, no entanto, combater e rechaçar as experiências de corpos e sexualidades divergentes.

\section{Homens, masculinidades e homofobia}

De estudos que mostraram que a adesão e identificação de determinados grupos a um padrão hegemônico de masculinidade implicava em "desvantagens" no "ser homem", emergiu a compreensão de que "tornar-se homem" poderia significar um processo doloroso, de adoecimento e submissão a um sistema que supostamente os oferecia poder e facilidades, num contraponto à própria expectativa de onipotência masculina referenciada ao grupo (GIFFIN, 2005; PIMENTA, 2013; TONELI et al., 2010). Os primeiros homens a coadunarem às ideias dos estudos feministas foram justamente os gays, pela constatação da opressão advinda da obediência dos grupos de homens aos valores patriarcais. Os "estudos gays" e os estudos feministas contribuíram de forma peculiar com produções que redefiniram e ampliaram o próprio conceito de masculinidade (GIFFIN, 2005; GOMES, 2008; PISCITELLI; SIMONI, 2015).

Podemos incorrer em dois equívocos quando pensamos a masculinidade: um é associá-la à palavra homem e o outro é confundi-la com virilidade. Detentora de

1 Lésbicas, Gays, Bissexuais, Travestis, Transexuais e Intersexuais. 
um lugar simbólico, a ideia de masculinidade construiu-se como oposição, negação e inferiorização do feminino. Apoiada simultaneamente com os significados sobre "ser mulher" apontam para a construção de práticas sexistas e homofóbicas donde grupos de mulheres (cis e trans) e não heterossexuais se tornam projeções sobre um lugar de não-ser, numa tentativa exagerada de alguns homens afirmarem-se como "não mulher" (NOLASCO-SILVA; ROSSATO, 2017; KIMMEL, 1998; SANTOS; ZAGO, 2013).

As discussões sobre as masculinidades têm apresentado debates sobre o conceito de masculinidade hegemônica e suas dimensões subalternas (NOLASCOSILVA; ROSSATO, 2017; KIMMEL, 1998; PISCITELLI; SIMONI, 2015; RODRIGUEZ et al., 2016; TORO-ALFONSO; DÍAZ, 2006). Buscando fortemente excluir qualquer atributo e/ou comportamento associado ao feminino, a masculinidade hegemônica organiza-se a partir da heterossexualidade e, desse modo, a homofobia (apoiamo-nos no conceito de BORRILLO ${ }^{2}$, 2010) torna-se um elo legítimo na relação entre homens e destes com o mundo (GOMES, 2008; TONELI.; ADRIÃO, 2005). Sobre isto, afirma Vale de Almeida (200o) que "no campo do gênero, trata-se da capacidade de impor uma definição específica sobre outros tipos de masculinidade, o que significa que o modelo exaltado corresponde, na realidade, a muito poucos homens" (p. 155).

No Brasil, é corrente a ideia de masculinidade afirmada através da posição ativa em situações de intercurso sexual. Esta hierarquia de práticas sexuais, que situa no topo de sua pirâmide os homens heterossexuais, funciona interpelada de outros atributos, tais como aparência e status socioeconômico, o que influencia diretamente na construção de uma sociabilidade gay e na maneira com que grupos de LGBTI constroem e dão sentido às suas vidas. Estudos publicados por CerqueiraSantos e DeSouza (2011) revelaram que as mulheres heterossexuais mostram menos preconceito sexual do que homens heterossexuais, o que evidencia o temor do homem brasileiro de serem percebidos como "pouco masculinos", ou ainda, como femininos.

Optamos por compreender a(s) masculinidade(s) evitando qualquer explicação que tendencie para as ideias de estado ou natureza do ser. Preferimos considerála por meio dos valores, condutas, práticas, comportamentos e características que, em contextos culturais e históricos específicos, são associadas a determinados grupos ou indivíduos que negociam constantemente bens simbólicos, econômicos e culturais. Ressaltamos que a(s) masculinidade(s) participam das políticas de gênero e, dessa forma, operam na regulação e no controle das condutas. Compreendê-la também é considerar outros recortes que a alimentam, tais como classe, etnia, orientações sexuais, ciclos de vida e como esses fatores se articulam na composição dos jogos de poder (NOLASCO-SILVA; ROSSATO, 2017; KIMMEL, 1998; PISCITELLI,

2 Borrilo (2010) comenta que os movimentos sociais LGBTI no Brasil afirmam a utilização das expressões lesbofobia e transfobia para referirem-se às práticas hostis e agressivas direcionadas a lésbicas, travestis e transexuais, numa variação do termo homofobia. No entanto, estas práticas hostis e segregacionistas, trabalhada por Borrilo (2010) sob o termo de homofobia, possuem o mesmo sentido e significado para os diferentes grupos de LGBTI. 
SIMONI, 2015; RODRIGUEZ et al., 2016; CONNEL, 1995; NORIEGA, 2015; CONNEL, MESSERSCHMIDT, 2013).

\section{Sexualidades, homossexualidades e travestilidades}

Prado e Machado (2008), ao defenderem a construção das sexualidades e das identidades sexuais relacionadas às interações que se estabelecem em contextos culturais, sociais e políticos específicos, atestam a inviabilidade de uma explicação satisfatória e generalizante a respeito da homossexualidade, ao problematizarem o próprio termo a que se referem. Para os autores, a homossexualidade significa uma "experiência identitária contemporânea construída na tensão entre valores da esfera privada e da esfera pública” (p. 19). Guerrero (2007), Ribeiro (2005), Miskolci (2007) e Trevisan (2007) também assinalam a forma com que os aparatos da ciência médica e criminal participam da criação da homossexualidade no final do século XIX, patologizando suas expressões e criminalizando suas práticas.

Ao produzir a estigmatização do homossexual enquanto um contraventor da natureza, todos aqueles que fugiam à norma heterossexual vigente poderiam sofrer com o asilamento, a privação de liberdade ou mesmo com a imposição de tratamentos, que visassem à supressão ou redirecionamento do desejo homoafetivo (GUERRERO, 2007; RIBEIRO, 2005; MISKOLCI, 2007; TREVISAN, 2007). Os autores sugerem que a homossexualidade sempre anunciou a ameaça à ordem e, com essa possibilidade, erigiam as respostas ideológicas e as práticas repressivas para sua contenção. Portanto, a homossexualidade, ou melhor, as identidades sexuais e sexualidades só podem ser percebidas pela consideração da dimensão moral presente na construção social e histórica da sexualidade. (GUERRERO, 2007; RIBEIRO, 2005; MISKOLCI, 2007; TREVISAN, 2007).

Toro-Alfonso (2005) adverte que as homossexualidades se inserem na fluidez, complexidade e diversidade das construções sociais sobre a masculinidade e a feminilidade, uma vez que a construção do sujeito homossexual se dá no espelhamento com a heterossexualidade e desta com a masculinidade hegemônica. Desta forma, a apreensão dos significados das homossexualidades interage diretamente à discussão acerca das masculinidades. Dentro deste contexto, Bello (2010) afirma que a homossexualidade masculina é um aprendizado que se obtém através da história e da cultura cuja posição (biológica) do gênero exerce forte influência para a construção das masculinidades.

Para Bello (2010), a masculinidade é entendida como um conjunto de mandatos institucionalizados que exigem e obrigam indivíduos a serem homens, a justificativa para as práticas ditas "homofóbicas" também remete a uma história da homossexualidade que é contada, pela cultura, pela "masculinidade heterossexual". As travestis contribuem, neste caso, para a construção de uma lógica da alteridade muitas vezes carregando o desafio de romper com o binarismo sexual e de gênero ainda 
que negociem e se identifiquem a categorias normativas para masculino e feminino. (SILVA; BARBOZA, 2005). Também assinaladas por definições biomédicas, afirmamse em políticas de estado para saúde muitas vezes rejeitando a lógica prescritiva desses programas (FERNANDES et al., 2017; SAMPAIO; GERMANO, 2017).

Atualmente as homossexualidades, travestilidades e também heterossexualidades anunciam que as possibilidades de compreensão da construção social das sexualidades e identidades sexuais sugerem a inclusão de outros elementos para além do eixo da sexualidade enquanto aspecto estruturante dos gêneros e orientações sexuais (MARSIAJ, 2003). Concordamos com Del Río (2006), que afirma que um questionamento da heterossexualidade e da homossexualidade libertará não somente algumas minorias, mas também homens e mulheres que não querem seguir os modelos dominantes de masculinidade e feminilidade, modelos estes sustentadores da própria definição de heterossexualidade.

\section{A Teoria das Representações Sociais}

O conceito de representação social surge num contexto de insatisfação dentro da Psicologia Social de meados do século passado. É pela proposta de análise psicossocial do conceito de representação social que ressalta o caráter inventivo da teoria (MOSCOVICI, 2001). De maneira geral, a Teoria das Representações Sociais oferece a possibilidade de análise de processos vividos e simbolizados pelo sujeito em relação de interação e comunicação com seu entorno. As representações são modos de pensamento, elementos fundamentais à compreensão dos processos intra e interindividuais, engendrados em contextos histórico, social e econômico específicos.

A representação social, por referir-se a um conteúdo que é socialmente elaborado e partilhado, relaciona-se às formações ideológicas e às expressões destas nas formações cognitivas de maneira que o sujeito que representa também se torna alheio às formas e condições da formação do conhecimento que participa (CABECINHAS, 2004). Este conhecimento, elaborado e partilhado, localizado historicamente e pela cultura, possui como interesse principal atender às demandas da vida prática, sem compromisso com a crítica e a formalização do seu processo, definindo o que Rouquette (2005) determina por pensamento social.

Moscovici (2004) pontua as duas principais funções das representações: a primeira seria dar forma a um objeto estranho adequando-o a uma categoria previamente conhecida a fim de interpretar a imagem e/ou informação nova; a outra seria o controle da realidade a partir de um sistema prescritivo para interpretação que perdura através do tempo garantindo a reprodução de códigos e condutas constituindo o estatuto da memória social.

Assim, a representação social será sempre uma referência a um determinado objeto restituído simbolicamente pelo sujeito. Dessa forma, esse mesmo sujeito atribui sentido ao novo que se incorpora, revelando a interface da atividade simbólica 
e significante na construção da representação (JODELET, 1986). Vala (1997): "referemse a um fenômeno comum a todas as sociedades a produção de sentido" (p. 354). Entendemos que o enfoque dado à atividade psíquica é base fundante da teoria em Representações Sociais.

Por envolver processos sociocognitivos, que afetam práticas e atendem aos sistemas de orientação e identificação do sujeito, negando qualquer explicação que pretenda ser absoluta acerca de um objeto, a utilizamos neste estudo pelas possibilidades teóricas e metodológicas que apresenta à investigação das representações de masculinidades e suas conexões com as discussões acerca do preconceito, discriminação e do amor, propostas para este trabalho.

\section{Método}

Esta investigação possui um desenho quantitativo e contou com um total de 131 participantes que responderam a um questionário por escrito com questões abertas e fechadas. Utilizamos o ALCESTE (Analyse Lexicale par Contexte d'um Ensemble de Segments de Texte), software desenvolvido por Reinert (1990), que se adequa bem a pesquisas que possuem grande volume de dados de texto. O ALCESTE articula métodos estatísticos, tais como a Classificação Hierárquica Descendente e a Análise de Correspondência e, por isso, pode ser definido tanto como uma técnica quanto por uma metodologia para análise textual (MENANDRO, 2004).

\section{Participantes}

Participaram deste estudo 52 homens gays, 40 heterossexuais e 39 travestis. Em relação aos critérios de inclusão para participação na pesquisa, definimos: com idades a partir de 18 anos, possuir qualquer nível de escolarização e incluir-se nas categorias definidas por homens gays, heterossexuais e travestis. Dos 40 participantes heterossexuais, 30 estavam com idades compreendidas entre os 18 aos 24 anos e 10 acima dos 24 anos. Destes 40, 32 possuíam ensino médio (em curso ou concluído) e 8 participantes ensino superior.

Entre os 52 homens gays, 30 (58\%) estavam na ocasião da pesquisa com idades entre 18 e 24 anos e 22 (42\%) com idades acima dos 24 anos. Apenas dois possuíam o ensino fundamental como formação escolar, 30 participantes (58\%) cursavam ou cursaram o ensino médio e os outros 20 (40\%) cursavam ou cursaram o ensino superior. Das 39 travestis, 35 estavam com idades acima dos 24 anos, portanto, um grupo caracterizado por participantes mais velhas. Em relação à escolaridade, apenas uma possuía o ensino superior. Das restantes, 20 possuem o ensino fundamental (completo ou incompleto) e 18 possuem o ensino médio (completo ou incompleto). 


\section{Instrumentos}

Utilizamos um questionário composto de 16 questões - 14 abertas e 2 fechadas. As questões estavam organizadas em três blocos temáticos de perguntas. O primeiro bloco abordou percepções e crenças dos participantes sobre "ser homem" e "ser mulher". O segundo bloco consistiu em perguntas sobre "amor" e "sexo" e o terceiro bloco abordou questões sobre preconceito e discriminação. No cabeçalho do questionário foram preenchidas informações sobre idade, escolaridade, profissão ou ocupação e autoidentificação dos participantes nas categorias: gays, heterossexuais, travestis, transexuais ou bissexuais.

\section{Procedimentos}

As estratégias utilizadas para a seleção de interessados(as) foram: divulgação da pesquisa através de contatos das pesquisadoras e agendamento com os participantes que manifestaram interesse e disponibilidade; aplicação dos questionários em salas de aula (nesse caso, pudemos dispor de turmas de medicina e farmácia de uma universidade pública brasileira); utilização dos recursos do Google Docs ${ }^{\circledast}$ para divulgação e preenchimento do questionário online. Os questionários foram respondidos por escrito, exceto pelo grupo das travestis ${ }^{3}$. Nestes casos, os questionários foram gravados e feitos oralmente. As gravações em áudio foram posteriormente transcritas e o banco de dados construído conforme as regras estabelecidas pelo programa de análise textual utilizado.

\section{Análise dos dados}

Consideramos que a utilização do ALCESTE em pesquisas sobre Representações Sociais é interessante, pois o programa permite visualizar que o "uso de um vocabulário específico é visto como uma fonte para detectar maneiras de pensar sobre um objeto" (KRONBERGER; WAGNER, 2002, p. 427). De acordo com Camargo (2005), um corpus deve ser monotemático para que sejam adequadas às análises do ALCESTE. Neste momento, definimos como variáveis para construção do banco de dados a identificação no grupo $(\mathrm{G}, \mathrm{H}$ ou T), a idade (acima ou abaixo dos 24 anos de idade para delimitar os participantes entre jovens e não jovens) e escolaridade (níveis: fundamental, médio e superior). Assim, para cada grupo pesquisado construímos três bancos de acordo com a divisão por temas contida no questionário.

3 Atribuímos este fato ao baixo índice de escolaridade que as participantes possuíam. 


\section{Considerações éticas}

Informamos que foram respeitados os preceitos que definem os critérios éticos necessários em pesquisas com seres humanos tal como preconizados na Resolução no 466, de 12 de dezembro de 2012, sendo esta a atualização da resolução 196/96 do Conselho Nacional de Saúde do Brasil. Dentre as exigências da resolução estão: anuência de forma esclarecida e voluntária das participantes; garantia de sigilo e privacidade; garantia de recusa à participação e retirada do consentimento; relevância social da pesquisa. Tais exigências encontram-se no Termo de Consentimento Livre e Esclarecido que foi apresentado a cada participante antes da resposta ao questionário.

\section{Resultados}

O software ALCESTE apresenta os resultados de suas análises indicados por: porcentagem de aproveitamento do conteúdo textual de cada banco de dados seguido por gráficos com os radicais das palavras mais recorrentes dividindo-as em classes e a força da ligação entre si (dendrograma), gráfico representado por quatro quadrantes que indica a força de ligação entre as variáveis inseridas nos bancos e as Unidades de Contexto Elementar (UCE), que são a repetição de trechos de texto inseridos no banco relacionado às outras apresentações gráficas indicadas acima. Optamos, para melhor aproveitamento na apresentação dos argumentos da pesquisa, por apresentar aqui somente alguns exemplos das UCE das classes encontradas.

\section{Homens cis heterossexuais:}

"Ser Homem”, "Ser Mulher"

Com um aproveitamento de $72,84 \%$ do conteúdo segmentado em 4 classes estáveis. A classe 1, que denominamos de "funções sociais do ser homem e ser mulher" caracteriza-se pelos papéis que um homem deve assumir para ser reconhecido enquanto tal. Na classe 2, estão presentes as relações que apontam para a correspondência entre sexo de nascimento e orientação sexual. Assim, para estes, definir homens e mulheres corresponde à identificação do sexo biológico e a este acompanha a orientação sexual heterossexual.

2218 Indivíduo do sexo feminino, com órgão reprodutor feminino, que relacione-se unicamente com indivíduos do sexo oposto! heterossexuais! Presença de órgão reprodutor feminino completo, de nascença! E preferência sexual heterossexual! Sua preferência sexual heterossexual, sua forma de pensar e agir com relação a essa preferência! 
Nomeamos o eixo de associação entre as classes 1 e 2 de "correspondência entre identidade de gênero, sexo e orientação sexual”. Observamos que as relações nas Unidades de Contexto Elementar (UCE) revelam um caráter evolutivo, justificada nos argumentos pelo desenvolvimento natural da espécie, cuja socialização parece acompanhar, ou seja, associa-se a esse plano evolutivo o biológico, sociológico e moral: o homem deve madurar, trabalhar e escolher uma fêmea para reproduzir e constituir família. Esta reflexão acompanha as UCE presentes na classe 3 e 4, que apresentam uma tentativa de diferenciação dos sexos a partir daquilo que assegura a não contradição, ou ainda, a tentativa de evitar rupturas e ambiguidades na compreensão de sexo e gênero amparando-se nas constatações recorrentes e difundidas ao longo dos anos pelas ciências médicas e da saúde.

8322 em termos fisiológicos, homem é aquele que difere quanto presença de estruturas como pênis, testículos, presença ou ausência de graus de hormônios, e algumas características corpóreas.

Os homens heterossexuais representam a masculinidade e a feminilidade ancorando-a em explicações deterministas, que utilizam o argumento de relacionar as diferenças biológicas entre os sexos a condutas que ambos os sexos deverão assumir para a vida em sociedade. Nesse sentido, se destacam a constituição de família, onde o maior objetivo está na reprodução (homem) e manutenção da espécie (mulher). A orientação sexual heterossexual atua como elemento balizador deste discurso e assume força para explicação das diferenças entre sexos e gêneros tanto quanto os argumentos calcados na biologia.

\section{“Amor e Sexo”}

Com $85,08 \%$ do conteúdo analisado, obtivemos 6 classes respectivas às falas dos participantes heterossexuais sobre amor e sexo. Há uma forte associação entre sexo e poder, entendida enquanto componente da masculinidade e primazia na identidade masculina. Esse aspecto afeta a forma como os homens encaram relações amorosas, se autoavaliando sempre como um objeto distante a ser conquistado pela mulher, que guarda o potencial para o amor e a manutenção da relação. Especificamente as classes dois e três trazem aspectos que relacionam a agressividade, a violência e a ousadia à construção da identidade. A classe quatro reafirma o sentido de oposição sobre a qual as identidades masculinas e femininas são construídas, nesse contexto, o homem se constitui em oposição à mulher da mesma forma que o sexo se encontra em oposição ao amor. Vemos a tendência à afirmação da masculinidade pelo sexo, que implica não só a quantidade, a liberdade para ter várias parceiras, mas também pela maneira ousada como 
homens escolhem ter suas experiências, assumindo que estas poderão lhes colocar em situações de risco.

Sobre esse aspecto, autores que discutem a relação entre violência, cuidado com a saúde e masculinidade afirmam que a construção de uma imagem positiva de si implica, para os homens, em alguém forte, sem vaidade e que assume os riscos (SANTOS et al., 2011). Importante dizer que as classes dois e três concentram sujeitos com idades abaixo dos 24 anos e segundo grau completo. Já nas classes um e cinco estão caracterizadas as UCE de sujeitos que possuem curso superior e idades acima dos 24 anos. Podemos inferir, pela análise da classificação hierárquica descendente, que encontramos uma associação entre risco, violência e juventude, elementos que sugerem a relação da agressividade e ousadia não só à masculinidade, mas desta com o elemento geracional, reforçando um imaginário de que os jovens são, pela idade, irresponsáveis e impulsivos.

Se por um lado as relações amorosas atuais parecem abrir espaço ao diálogo e à negociação, a forma como os homens compreendem o sexo, como um elemento constitutivo da natureza masculina, os incentiva à defesa de posições onde a liberdade individual masculina e submissão da mulher ao comportamento "predador" do homem é valorizada. Nesse sentido, as práticas sexuais configuram-se pela manutenção e defesa da dominação masculina num mundo de relações e papéis sociais cada vez mais iguais. A ausência de respostas deste grupo sobre questões de preconceito quanto à orientação sexual e identidade de gênero, nos fez refletir que experiências de discriminação vividas podem alterar a forma como grupos distintos constroem representações sobre masculinidade e amor.

\section{Homens cis Gays: \\ "Ser Homem”, “Ser Mulher"}

No banco dos homens gays obtivemos quatro classes estáveis e um total de $81.35 \%$ de aproveitamento do conteúdo. Há presença de discursos que corroboram as crenças no determinismo biológico para diferenciação sexual (classe 1), onde homens e mulheres são seres biológicos opostos e a condição de macho ou fêmea é dada ao nascer e amparada em diferenças genéticas. Constatamos que também no grupo de homens gays é forte a referência às definições apontadas pela biologia para definição dos sexos e gêneros. No entanto, esse discurso mostra suas descontinuidades pela análise da classe 4 que enfatiza as liberdades e possibilidades para construção de identidades de gêneros.

6538 ente biológico feminino, oposto ao ente biológico masculino. Características puramente biológicas: cromossomos, hormônios.

2221 também há o sentir-se, o ver-se como. uma pessoa pode ter nascido, e ser considerado a princípio, homem ou mulher, 
mas ao longo da vida poder sentir-se como do outro gênero e daí, buscar, o que normalmente acontece, adequar-se ao que a sociedade considera homem ou mulher.

Em destaque as classes que obtiveram maior força de conteúdo para análise observamos que os discursos da classe 1 e 3 se opõem aos da classe 2 e estes aos da classe 4, nos mostrando três aspectos importantes para a definição da compreensão dos participantes acerca do ser homem e ser mulher: determinismo biológico, identidade de gênero e responsabilidade moral. Importante notar que o discurso que tende para os aspectos morais e, portanto, relativizador das diferenças entre os sexos é típico de homens jovens, com idades entre 18 e 24 anos. As classes que apontam para o determinismo biológico são típicas de sujeitos acima dos 24 anos. Tal aspecto sinaliza a possibilidade de ressignificação dos estereótipos de gênero por sujeitos mais jovens.

\section{"Amor e Sexo"}

Com $83,87 \%$ de aproveitamento do conteúdo e seis classes encontradas, enfatizaremos as que apresentaram maior força para análise. As classes 5 e 6, cuja força de associação entre ambas é de 8o\%, trazem elementos que reforçam a associação da masculinidade com características de comportamento relacionadas à agressividade e à violência, mas também relativizam a postura naturalmente viril atribuída aos homens. Observamos que, ser ativo no sexo, diferença simbólica que relaciona prática sexual a papéis de gênero tão valorizada em nosso contexto cultural, por ser afirmadora da masculinidade, deixa de ser um elemento importante. Desse modo, ainda que os participantes relatem que os homens são mais ousados no sexo, aproximando-os de comportamentos de risco, aspectos preditores de um conceito de masculinidade hegemônica (como o papel ativo no sexo anteriormente valorizado) aparece flexibilizado.

Denominamos esse eixo de classes associadas de "virilidade gay", por comportar tendências à desestabilização do padrão hegemônico de masculinidade relativizado pelas práticas sexuais relatadas e pelo autorreconhecimento de si a partir de uma identidade gay, que admite, portanto, a presença de atributos entendidos como "femininos". Tal como apresentado pelos homens heterossexuais, o amor é representado como um elemento tipicamente feminino, sobre o qual os homens não se identificam. Já o sexo encaixa-se sobre o campo do masculino, cuja prática constante e exibicionista funciona como um artefato garantidor da masculinidade. Da mesma forma, a submissão está para o amor como a dominação está para o sexo, intensificando as fronteiras que diferenciam as identidades femininas das masculinas.

Como no grupo de heterossexuais, as representações sociais de masculinidade e amor se constroem associadas, onde o entendimento do amor o 
torna um campo estranho aos homens, que recorrem ao sexo como afirmação de si e em detrimento da ampliação de experiências com manifestações de carinho e ternura. O amor e o sexo, tal como vivido pelos homens gays, contribuem para a manutenção dos binarismos de gênero, através do recurso de práticas e justificativas de comportamentos estereotipados para ambos os sexos, ainda que haja a inclusão de argumentos relativizadores destas diferenças. Privilegiam uma postura que amplia as possibilidades e experiências que cada sujeito pode ter acerca de seu corpo e suas formas de encontrar prazer, integrando a racionalidade moral a conforto psicológico que pode ser adquirido por e para si, cuja coerência articula-se à ordem do desejo e não da biologia científica. Justamente na experiência desviante do desejo que compreendem, muito mais que os heterossexuais, as possibilidades de um mundo sexo-diverso.

\section{“Discriminação e Preconceito”}

As experiências dos participantes gays sobre discriminação e preconceito originaram três classes estáveis (e 74.36\% de aproveitamento do conteúdo) a partir das operações realizadas pelo ALCESTE. Na classe 1, são marcantes as experiências de rejeição vividas pelos participantes nos contextos e relações de amizades, trabalho, estudo e família. A experiência da discriminação congrega a vivência da rejeição à construção do respeito nessas mesmas relações.

11628 minha chefe sabe que sou gay e me respeita acima de tudo, por não ser afeminado nem falar fino, tenho respeito de todos do meu trabalho.

Pela associação da classe 2 com a classe 1 constatamos que a relação entre "ser gay" e "homofobia" revela-se pela apreensão de manifestações de rejeição do entorno social, sendo a escola um espaço marcante dessas manifestações. Nesse contexto, a constatação de um "jeito gay" por parte de colegas e membros do corpo escolar é acompanhada da interdição na manifestação de afeto entre homens. Sobre esse aspecto os participantes ressaltam detalhes das relações de amizade acentuando a rejeição sentida quando, de fato, a orientação sexual é revelada ao amigo ou colega.

A classe 3 denominamos de "Preconceito e Cultura", necessidade apontada pelos participantes da superação do preconceito através da educação, capaz de fomentar uma mudança cultural. Nesse sentido, o preconceito e a discriminação sentidos através de agressões verbais, gestos e olhares advém, principalmente, de pessoas estranhas, gerando fortes sentimentos de humilhação. "Os preconceituosos" aparecem como um grupo difuso na sociedade e em alguns momentos são identificados sob a alcunha de "fundamentalistas religiosos" e/ou pessoas "sem 
cultura”. O preconceito é entendido como um elemento cultural natural na nossa sociedade, mas que pode e deve ser vencido através da informação e educação.

A reação a estas situações oscila entre a submissão e a argumentação. A submissão é a escolha feita quando ainda se percebe a fragilidade da condição vivida e o medo da violência física. Esclarecemos que a classe 3 está caracterizada por UCES de indivíduos jovens, com idades entre 18 e 24 anos, o que deve justificar a ausência de uma postura mais autônoma em relação a sexualidade. Por outro lado, a argumentação é justamente o caminho através do qual buscam afirmar direitos e reconhecimento da igualdade.

166 uma única vez em que sofri agressão verbal, sendo chamado de veado na rua, senti-me extremamente aviltado e humilhado, mas nada fiz por temer reação violenta.

As representações sociais de masculinidades de homens gays ancoramse nos discursos científicos que apregoam o determinismo biológico para diferenciação dos sexos. A biologia, mais do que traduzir as experiências reais de homens gays em suas vivências de amor, sexo, trabalho, amizades, família, recoloca o discurso de uma masculinidade que se estrutura em torno da expressão da violência, da força e da dominação pelo sexo. Ao repor a dominação, objetivada na imagem do predador sexual, como discurso natural à masculinidade e aos homens, também o recriam, posto que a experiência de "ser gay" permite associar significações atípicas ao homem comum. Dentre essas experiências do "ser gay" destacamos o preconceito e discriminação enquanto balizadoras da construção de uma masculinidade que busca sua aprovação pela aproximação, ainda que frágil, a um padrão construído em direta oposição ao que pode ser identificado como pertencente ao mundo das mulheres.

Nesse sentido, a cobrança social e cultural de comportamentos que respondam à imagem do predador sexual os convence da inabilidade masculina para o amor, representado sob os signos da submissão, da fraqueza e da feminilidade. $\mathrm{Na}$ tentativa de afastarem as identificações com o mundo feminino reforçam padrões socioculturais que impedem a manifestação de afeto entre homens e os impele a práticas que mais os vulnerabilizam do que fomentam a proteção de si. Ao impedirem as manifestações de afeto entre homens, importantes instituições socializadoras como a família e a escola cumprem eficazmente suas funções de vigilantes dos corpos desviantes, tornando-os falsamente assépticos em relação ao amor e à expressão de sentimentos, como também permitem e naturalizam manifestações violentas direcionadas ao grupo de homens.

No entanto, também as experiências de "ser gay" fundamentam a relevância dada pelos participantes às possibilidades de autoidentificação/reconhecimento e de construção de si como sujeitos masculinos/femininos. Ao admitirem a existência de modelos sexo-diversos, provocam a suspensão das diferenciações 
e hierarquias estabelecidas entre os gêneros, desestabilizando parte do discurso evolutivo-biológico, sustentador do modelo binário diferenciador para sexos e gêneros.

\section{Travestis:}

\section{"Ser Homem”, "Ser Mulher"}

Após tentativas de análise realizadas com o software ${ }^{4}$, este banco de dados gerou 4 classes estáveis e teve um aproveitamento de $63 \%$ do conteúdo. A classe 1 registra que as diferenças entre homens e mulheres estão apenas nos órgãos sexuais e no comportamento. A referência feita aos órgãos sexuais e ao comportamento retrata a experiência das participantes em relação ao seu próprio corpo. Dessa maneira, as participantes afirmam que é possível ser mulher mesmo tendo nascido homem e com isso diminuem a distância que opõe masculino e feminino ao imprimirem esta ambiguidade aos seus corpos e suas identidades.

Enfatizam o papel da mulher chefe de família reconhecendo nela características que a diferenciam do homem não por uma perspectiva biológica, mas histórica. No discurso das travestis, a mulher historicamente escravizada e objetificada ganhou espaço e reconhecimento social e, por suas conquistas adquiridas, supera o homem em competências intelectuais e psicológicas. As travestis recheiam de aspectos positivos a imagem feminina caracterizando-a como trabalhadora, dona de casa, mãe, lutadora e guerreira. Se a classe 1 enfatizou o trabalho fora de casa, a classe 3 repõem a mulher em seus papéis sociais tradicionais: cuidar da casa, do marido, dos filhos, mas que tem garra suficiente para lutar por si mesma.

Ao contrário dos homens heterossexuais que veem a mulher como alguém que precisa da proteção masculina, para as travestis, é o homem quem necessita e recebe os cuidados da mulher. Neste eixo de classes o homem aparece como coadjuvante da mulher, visto como alguém mais fraco que apenas cumpre suas responsabilidades. A este eixo de classes denominamos de "a força da mulher". A classe 2 representa a fantasia, o objeto de desejo das travestis. Por empreenderem um longo trajeto na transformação do corpo e na apreensão de códigos e comportamentos entendidos como femininos, o homem, para as travestis, é alguém que, acima de tudo, deve causar uma “impressão máscula”.

4 Cumpre informar que os bancos de dados das travestis foram revistos por diversas vezes até que conseguíssemos um melhor aproveitamento do conteúdo e estabilidade entre classes. Atribuímos esse fato à utilização do gravador, o que permitiu às travestis fornecer muitas informações via oral, mas também gerou uma dispersão nos objetivos das questões, causando uma heterogeneidade muito grande no discurso que precisou ser minimizada através de cortes nas transcrições realizadas, especialmente os que se referiam à descrição de histórias e experiências que fugiam ao conteúdo abordado pelo questionário. 
$617 \mathrm{O}$ homem para mim e um atrativo, mas não é um atrativo só sexual. olho um homem como se fosse uma mulher olhando um homem. Não e olhar o sexo biológico, olhar a cara bonita. Eu olho ele como um todo. Lógico que eu vejo beleza masculina, eu vejo tudo.

As definições usadas pelas travestis para homens e mulheres são estereotipadas e mostram que uma "imagem feminina” deve se diferenciar de uma "imagem masculina”. Essa diferenciação estereotipada se dá pela via do desejo, que faz com que este "corpo trans", para que tenha êxito em seu projeto de feminilidade, deva ser olhado e desejado por um homem de verdade, cuja imagem tem na virilidade seu aspecto principal. Neste sentido, constatamos que o grupo das travestis não utiliza o determinismo biológico como argumento fundante da diferenciação de homens e mulheres. Isso se explica pela própria experiência "trans", cuja vida é marcada pela construção do feminino num corpo masculino. A experiência real da transformação do corpo imprime a possibilidade da duplicidade (nem homem, nem mulher) na construção dos corpos e identidades de gênero.

A ideia de correspondência entre um sexo de nascimento (macho), identidade de gênero masculina (fortemente marcada por atributos de uma masculinidade hegemônica) e orientação sexual heterossexual é bastante presente no grupo de homens heterossexuais, em menor intensidade no grupo de homens gays e fraca no grupo de travestis. Por não seguirem o seu destino como homens, as travestis fazem mais referências à feminilidade, a traduzindo sempre como uma experiência positiva, fixada numa imagem altamente valorizada da mulher. O campo do masculino significa, então, um campo de conflito. A forte referência à conduta que um homem deve ser para ser reconhecido enquanto tal (honesto, trabalhador) remete à socialização que receberam como meninos e homens. Tais aspectos, por não se relacionarem exclusivamente a um corpo masculino, puderam ser incorporados em suas identidades, o que não ameaça o projeto feminino que construíram para si.

\section{"Amor e Sexo"}

Com 5 classes estáveis e $77 \%$ de aproveitamento do conteúdo, realçaremos nessa discussão as classes 1 e 5 . A classe 1 ressalta as diferenças entre homens e mulheres em relação às experiências sexuais. Tal como constatado nos dados relativos aos homens gays e homens heterossexuais, o sexo aparece como artifício de domínio e prática natural e instintual dos homens. No outro oposto, estão as mulheres e suas habilidades também inatas para o exercício do amor. Vejamos uma UCE típica da classe: 
19335 A mulher o sexo e amor, mesmo que tenha paixão no meio, mas ela liga mesmo para o amor.

A classe 5, aprofunda as diferenças sobre como homens e mulheres vivem o amor de maneira que repete e complementa conteúdos de classes anteriores $(2,3$, e 4), com argumentos que se aproximam ao grupos de homens cis heterossexuais e gays.

917 Hoje eles são mais volúveis, mas existem muitos homens com características maravilhosas. A mulher é mais sincera. Ela se entrega mais.

Da mesma forma que os homens gays e heterossexuais, as travestis constroem suas representações do amor alocando-a no universo da feminilidade, definindo-o como um universo de submissão, mas também de flexibilidade. Dessa forma, o sexo compõe as representações de masculinidades, expressão da dominação. Para os grupos pesquisados, sexo e amor são experiências típicas de um ou de outro gênero, representações que também contribuem para justificar as diferenças entre homens e mulheres.

\section{"Preconceito e Discriminação"}

As travestis configuram-se como um dos grupos mais discriminados da sociedade (CARRARA; VIANNA, 2006). Tal como no banco dos homens gays, as classes 1 e 2 revelam a escola como o espaço onde predomina a emergência de situações de preconceito e discriminação. Nesse contexto, o banheiro torna-se um lugar emblemático para as travestis por seu poder de demarcar as diferenças de sexo e gênero, cuja função cumpre regular e normatizar corpos. Sendo assim, corpos desviantes como são os "corpos trans" são condenados e impedidos de trânsito livre nesses espaços. Dinis e Lima (2009), afirmam que "é comum as escolas tratarem gênero e sexualidade como sinônimos, padronizando um modo único e adequado do que é o masculino e o feminino, possibilitando apenas uma maneira de viver a sexualidade" (p. 54).

Na classe 1, complementada pela classe 2, encontramos relatos de preconceito que são ocasionados pelo fato de serem percebidas como travestis. Essa discriminação configura-se através de olhares, gestos ou mesmo violência física. Advém de forma gratuita e relacionam-se ao impacto que a imagem "trans" causa ou pode causar. São frequentes os relatos de rejeição sofrida por parte de outros, especialmente ao tentarem usar o banheiro feminino, ainda que esta discriminação também seja sentida quando transitam por outros espaços e situações sociais. 
307 Ele percebeu que eu era um travesti, que eu não era uma mulher normal, e por isso ele fez isso comigo. Eu me senti arrasada, humilhada. Eu me senti um lixo. O que eu fiz? Eu tive que pegar a panela de pressão para eles passarem na máquina e eu poder ver o preço.

$\mathrm{Na}$ classe 3, que concentra o maior número de UCEs, fica evidente que a discriminação sentida como injúria provoca a tentativa da indiferença, um artifício que busca minimizar os efeitos nefastos do preconceito, naturalizando-o. Ainda que não percebam as consequências negativas dessa submissão às agressões verbais, estas implicam na não ascensão das travestis à categoria de cidadãs e ao impedimento ao trânsito social como indivíduos livres.

1099 Aqui mesmo passa muita gente que xinga, chuta que é macumba, vai bater uma laje! Humilha a gente de várias formas. Eu não ligo, eu dou o desprezo, eu ignoro.

A injúria, transformada na ideia de um preconceito menor, cerceia e restringe as possibilidades de uma vida social plena na medida em que contribui para determinar quando e onde os corpos trans podem ser vistos. Esse movimento as afasta dos espaços legítimos de reconhecimento social (família, escola, trabalho formal) e as joga para campos marginais, tal como a prostituição, onde são comuns as tentativas de anulação e apagamentos dos corpos e identidades trans. A tentativa de serem indiferentes às agressões verbais revelam-se como recurso psicológico de proteção a uma violência gratuita, cotidiana e naturalizada.

\section{Discussão e conclusões: Sobre cognição, binarismo e pensamento social}

Abric (200o) demonstra que a representação social possui um núcleo estruturante que terá como função organizar e estabilizar os elementos que a constitui, fornecendo sentido a este todo estruturado. Ademais, este núcleo estruturante resiste à mudança e incorpora elementos periféricos que relacionam a estrutura a situações concretas buscando adaptar-se às transformações do ambiente e defender a ideia central da representação de uma mudança radical. O núcleo estruturante (ou núcleo central) fundamenta-se em elementos históricos, ideológicos e sociais para sua constituição. Tem como base a coletividade e relaciona-se ao conjunto de normas e valores sociais. Já os elementos periféricos associam-se às contingências, ou seja, permitem a manifestação de aspectos individuais e de contextos locais, dando um tom personalizado às representações sociais (Abric, 2000). 
Concluímos que a representação social de masculinidade destacada possui elementos em comum nos três grupos trabalhados. Da mesma forma, as vivências típicas de cada grupo puderam ser constatadas a partir dos relatos dos participantes de suas compreensões acerca do amor e do sexo, e suas experiências de preconceito e discriminação por orientação sexual e identidade de gênero.

Assim, o discurso ancorador da representação social da masculinidade está na crença da diferenciação sexual e do determinismo biológico que não só diferencia, mas instrumentaliza identidades de gênero masculinas ou femininas. Laqueur (2001) sistematiza os períodos históricos sobre os quais foi possível à ciência fazer circular os resultados das investigações minuciosas sobre o corpo, como vemos acontecer ainda hoje, traduzida pelos avanços científicos da medicina e da capacidade desta ciência de fazer modificar seus níveis de especialização. Se a ideia compartilhada entre os participantes do estudo acerca da masculinidade configura o que parece ser o núcleo estruturante da representação da mesma, encontramos divergências nas experiências específicas de cada grupo, o que confirma a defesa de Abric (200o) quando ressalta que a particularidade das experiências individuais e grupais se mostra pela apresentação dos elementos periféricos da representação social.

Portanto, se o modelo de uma masculinidade hegemônica constrói o núcleo central da representação, é importante esclarecermos onde e como os grupos constituem os elementos que dão o tom e a cor à experiência singular de cada um. Neste contexto, os homens heterossexuais mostram-se fixos e defensores na ideia de que há uma correspondência presumida entre sexo biológico, identidade de gênero e orientação sexual, fortemente amparada nos discursos médico-científicos para diferenciação de sexos e gêneros. Para os homens gays a experiência singular da homossexualidade os faz buscar constantemente a adequação ao padrão heterossexual, numa tentativa de identificarem-se com o que a sociedade pré-determina como homem e evitarem o sofrimento causado pelo preconceito e pela discriminação. Dessa forma, apartam-se do mundo feminino a fim de não serem confundidos com mulheres, suportando apenas estas duas possibilidades de identificação, uma vez que homens e mulheres se definem num jogo de oposições. No entanto, este "ser gay" implica não só na busca de coerência para vivência do desejo, mas também outras dimensões, especificamente aquelas que as experiências de preconceito e discriminação causam. Nesse contexto de afirmação e questionamento de uma masculinidade ideal, admitem as práticas e possibilidades de experiências sexo-diversas, incluindo a ideia de que a aderência ao gênero se dá mais pela escolha do que pelo destino.

As travestis também reforçam o argumento do corpo físico para a diferenciação sexual e de gênero e a defesa de papéis rígidos e estereotipados para homens e mulheres. No entanto, a experiência da transformação torna real a ideia de um corpo flexível e plástico, enfraquecendo o discurso biológico determinista. Então, a masculinidade realiza-se pela defesa de uma conduta moral, retirando do corpo a responsabilidade de divisor de gêneros e tornando possível a experiência ambígua e (des)hierarquizante de ser homem e mulher ao mesmo tempo. Interessante observar 
que a experiência de socialização como homens faz os três grupos compartilharem as mesmas concepções acerca do amor e do sexo, sendo este último, o sexo, por onde expressam um conjunto de práticas e valores que manifestam o exercício da dominação (masculina) e poder sobre o qual nenhum grupo pesquisado quer abrir mão.

Outro aspecto importante refere-se à experiência de escolarização. É fato que as travestis são simbólica e concretamente expulsas do espaço escolar. Nesse sentido, a argumentação possível é da urgência de políticas afirmativas para retorno das travestis para a escola, como abertura de possibilidades de ascensão social pelo ensino e profissionalização. No caso dos homens, gays e heterossexuais, a juventude das amostras faz supor um momento de vida cuja escolarização tende a intensificarse em busca da formação profissional. Para os participantes a que tivemos acesso, o que observamos é uma defasagem na escolarização dos homens heterossexuais em relação aos homossexuais. Neste caso, a convergência da masculinidade, ou da resposta dos indivíduos à exigência de seu modelo, altera os planejamentos e projetos de ambos os grupos na busca de qualificação.

Os homens cis heterossexuais citaram a constituição de família como um elemento importante no tornar-se homem. Este fato os faz adiar suas ambições de qualificação pelo estudo buscando, talvez precipitadamente, trabalho e independência financeira. Por outro lado, habita o imaginário social, portanto, também dos gays, a ideia de que homossexuais não constituem família, o que torna mais sólido para o grupo o projeto de adquirir uma profissão e de desenvolver-se nela. Este aspecto também retoma a discussão iniciada neste trabalho de associação entre moralidade e construção da identidade social masculina, a partir de elementos constatados nas falas dos participantes que definem por homem o sujeito trabalhador, íntegro, honesto e de caráter, sugerindo a construção de uma moral/honra masculina.

Podemos apreender até aqui que o dispositivo gerador das representações sociais de masculinidades (e do amor) encontra-se na calcificação do binarismo sexual como discurso único e exclusivo, enunciado máximo em nossa cultura para apreensão de categorias tais como o sexo e o gênero, sobre cujas ideias as estruturas cognitivas irão se acomodar e serão por elas acomodadas. Esse discurso traduzido como verdade cognitiva, é eficaz na promoção do reconhecimento da vida e do mundo como um espaço familiar e habitável, mas esconde as forças ideológicas e políticas que o produzem. O binarismo - enquanto um sistema que ordena hierarquicamente diversas representações - determina um esquema cognitivo de pensamento sobre o qual o mundo é interpretado, mas também se associa a outros sistemas de representações, também binários, tal como a oposição entre natureza e cultura.

Por exemplo, nos resultados apresentados neste estudo são frequentes as referências às determinações biológicas/evolutivas (natureza) e as explicações projetivas (cultura) para diferenciação dos sexos e gêneros. Estes sistemas de representações não são acessados pelos participantes que permanecem alheios ao sentido metafísico destes grandes temas ordenadores dos códigos mentais e sociais. Camargo e Wachelke (2010) discutem esta arquitetura do pensamento social e 
afirmam que as representações sociais se relacionam entre si e estas a grandes temas que possuem o caráter de fazer avançar no tempo constructos ideológicos, tradições, crenças de longa duração que assumem a forma de oposição - tais como mulher/ homem; natureza/cultura - na estrutura da representação.

Sobre essa discussão, ao assumir que a sociedade pensa, Moscovici (2004) põe em evidencia o caráter ativo de cada sujeito na construção da representação, negando o caráter passivo que reduzia a complexidade das operações cognitivas envolvidas e a influência de sociólogos clássicos, que afirmavam a supremacia da ideologia na formação das subjetividades. No entanto, o próprio autor adverte para o perigo de exaltação de uma racionalidade normativa que não encara o caráter polifásico da cognição. Sendo assim, um tema será sempre rígido e pouco informará acerca do campo periférico da representação, marcado pelos julgamentos, sentimentos, relatos de experiências pessoais e grupais. Esse mesmo campo pode nos advertir sobre os elementos não-familiares que fomentaram a construção da representação.

No caso dos grupos deste estudo, a experiência com o preconceito e a discriminação possibilitou a percepção de aspectos dissonantes na representação social (ideal e hegemônica) da masculinidade e amor e no próprio entendimento do binarismo como tema justificador/balizador do discurso determinista biológico. Enquanto homens heterossexuais seguem à risca o padrão normativo, gays e travestis possuem outras formas de representação que admitem novas experiências (e representações) do corpo e das identidades de gênero. Não queremos dizer, com isso, que na abordagem às experiências de sofrimento tomamos um conteúdo mais rico e completo, mas a reflexão tendencia para a sutileza dos aspectos particulares de cada grupo e de como são importantes para o entendimento de como esses mesmos grupos comunicam suas representações sociais.

Toda pessoa LGBTI cresce e se desenvolve sob o signo da injúria. O capítulo V do Código Penal Brasileiro tipifica os crimes contra a honra, quais sejam: calúnia, difamação e injúria. Dentre estes, a injúria possui como característica o ataque à honra subjetiva de alguém, que dentro de um contexto de aplicação penal opõe-se à característica objetiva dos crimes de calúnia e difamação por estes implicarem no reconhecimento de um fato que seja falsamente imputado ou ofensivo à reputação de alguém. A injúria tida como crime, por amparar-se em ofensas à dignidade e ao decoro, envolve discutir quem é digno, ou melhor, se há o entendimento de que a dignidade é característica da condição humana, e quem é decente, quer seja devidamente percebido como sujeito que incorpora adequadamente as normas e os padrões morais.

Nesse entremeio, a percepção da injúria como "a violência que cala" pode ser determinante para o entendimento das práticas assumidas por gays, travestis e heterossexuais. As práticas, nesse contexto, foram determinantes para a compreensão sobre como estes sujeitos dizem de si e das representações que constroem. Como compreender a escolarização acentuada da amostra de homens gays senão pelo interdito "Gays não podem constituir família. Gays não podem ter filhos"? Como 
compreender os aspectos ritualizados das relações amorosas heterossexuais senão pela ideia de "Trabalhe, case e reproduza"?

Desenvolver-se sob o signo da injúria, repetida e cotidianamente por composições sociais diversas, recheia de negatividade as experiências identitárias fora de padrões. Tal como acontece com travestis e gays, a absorção silenciosa desse nãolugar social os motiva não só à busca desesperada a um padrão ideal de masculinidade e/ou feminilidade, mas à constituição de linhas de pensamento dissonantes, cuja força política não tem sido negligenciada por estudiosos do campo das sexualidades e militantes LGBTI. Portanto, em se tratando de pesquisas que intencionam abordar crenças, práticas e valores de comunidades sexo-diversas, defendemos que os sujeitos possam falar através dos instrumentos de pesquisa de suas experiências de desajuste, de fuga da norma, de estranhamento, de não-familiaridade. Sempre poderemos ter um traçado interessante e consistente dos temas ordenadores do pensamento social de toda a comunidade humana, como também dos elementos que furam a hegemonia destes mesmos temas.

\section{Referências}

ALBELDA, Joan Sanfélix. Las nuevas masculinidades. Los hombres frente al cambio en las mujeres. Prisma social, n. 7, v.1, dez., 2011, p. 220-247. Disponível em: https:// www.redalyc.org/pdf/3537/353744579008.pdf. Acesso em: 22 de junho de 2021.

ABRIC, Jean Claude. A abordagem estrutural das representações sociais. In: MOREIRA, Antônio Silva Paredes \& OLIVEIRA, Denize Cristina. (Orgs.). Estudos interdisciplinares de representação social. Goiânia: AB Editora, 2000, p. 27-38.

BELLO, Raul Balbuena. La construcción sociocultural de la homossexualidade. Enseñando a vivir en el anonimato. Culturales, n. VI, v. 11, 2010, p. 63-82. Disponível em: <https://www.redalyc.org/articulo.oa?id=69415134004>. Acesso em: 22 de junho de 2021.

BORRILO, Daniel. Homofobia: história e crítica de um preconceito. 1. ed. Belo Horizonte: Autêntica, 2010.

CABECINHAS, Rosa. Representações sociais, relações intergrupais e cognição social. Paidéia, n. 14, v. 28, 2004, p. 125-137. Disponível em: https://www.scielo.br/j/paideia/a/ v5LHqbWSsgTcDDy3XhrYVRv/?lang=pt. Acesso em: 22 de junho de 2021.

CAMARGO, Brigido Vizeu ALCESTE: Um programa informático deanálise quantitativa de dados textuais. In: MOREIRA, Antônio Silva Paredes; CAMARGO, Brigido Vizeu; JESUÍNO, Jorge Correia; NÓBREGA, Sheva Maia (Orgs.). Perspectivas teórico- 
metodológicas em representações sociais. João Pessoa/PB: Editora Universitária, 2005, p. 511-540.

CARRARA, Sérgio \& VIANNA, Adriana R. B. “ Tá lá o corpo estendido no chão...”: a violência letal contra travestis no município do Rio de Janeiro. Physis: Revista de Saúde Coleiva, n. 16, v. 2, 2006, p. 233-249. Disponível em: https://www.scielo.br/j/ physis/a/3TPLG3ckGKmShzJZdhCMRmd/?lang=pt. Acesso em: 22 de junho de 2021.

CAMARGO, Brigido \& WACHELKE, João. The Study of Social Representation Systems: Relationships Involving Representations on Aging, AIDS and the Body. Papers on Social Representation, n. 19, v.1, 2010, p. 21.1-21.21. Disponível em: https://psr.iscte-iul. pt/index.php/PSR/article/view/40o . Acesso em: 22 de junho de 2021.

CERQUEIRA-SANTOS, Elder \& DESOUZA, Eros. Preconceito e Discriminação contra minorias sexuais: o caso da homofobia. In: Techio, Elza Maria \& Lima, Marcus Eugênio Oliveira. (Orgs.). Cultura e produção das diferenças: estereótipos e preconceitos no Brasil, Espanha e Portugal. Brasília: Technopolitik, 2011, p. 247-275.

CONNELL, Robert W., MESSERSCHMIDT, James W. Masculinidade hegemônica: repensandooconceito.Estudosfeministas, n.21,v.1,jan../abr., 2013,p.241-282.Disponível em: https://www.scielo.br/j/ref/a/cPBKdXV63 LVw75GrVvH39NC/?lang=pt . Acesso em: 22 de junho de 2021.

DEL RÍO, José María Valcuende. De la heterosexualidad a la ciudadanía. AIBR: Revista de Antropología Iberoamericana, n. 1, v.1, jan. /fev., 2006, p. 125-142. Disponível em: https://dialnet.unirioja.es/servlet/articulo?codigo=1704217. Acesso em: 22 de junho de 2021.

DINIS, Nilson Fernandes \& LIMA, Francis Madlener de. "Pra que time ele joga?": a produção da identidade homossexual em um vídeo educativo. Arquivos Brasileiros de Psicologia, n. 61, v. 1, 2009, p. 49-59. Disponível em: https://www.redalyc.org/ pdf/2290/229019189006.pdf. Acesso em: 22 de junho de 2021.

GIFFIN, Karen. A inserção dos homens nos estudos de gênero: contribuições de um sujeito histórico. Ciência e Saúde coletiva, n. 10, v. 1, 2005, p. 47-57. Disponível em: https://www.scielosp.org/article/csc/2005.v10n1/47-57/pt/ . Acesso em: 22 de junho de 2021.

FERNANDES, Luís Antônio Bitante, BORGES, Águeda Aparecida Cruz, \& LÔBO, Rodolfo Pinheiro Bernardo. Travestilidadeàs avessas - a desconstruçãode uma 'paródia' identitária. Estudos Feministas, n. 25, v. 2, mai./ago., 2017, p. 473-494. Disponível em: https://www.scielo.br/j/ref/a/DJGrgYDRGvqFpGCfJgx7RSP/?lang=pt. Acesso em: 22 de junho de 2021. 
GOMES, Romeu. Sexualidade e masculinidade: a trama das palavras. In: GOMES, Romeu. Sexualidade masculina, gênero e saúde. Rio de Janeiro: Editora FIOCRUZ, 2008, p. 59-98.

GUERRERO, Ricardo de la Espriella. Homofobia y Psiquiatría. Revista Colombiana de Psiquiatría, n. XXXVI, v. 4, 2007, p. 718-735. Disponível em: https://www.redalyc.org/ pdf/8o6/80636411.pdf. Acesso em: 22 de junho de 2021.

JODELET, Denise. La representación social: fenómenos, concepto y teoría. In: Moscovici, Sérgio (Org.). Psicologia social II. Barcelona: Paidós, 1986, p. 469-494.

KIMMEL, Michael S. A produção simultânea de masculinidades hegemônicas e subalternas. Horizontes antropológicos, n. 4, v. 9, out./1998, p. 103-117. Disponível em: https://www.scielo.br/j/ha/a/B5NqQSY8JshhFkpgD88W4vz/?lang=pt. Acesso em:22 de junho de 2021.

KRONBERGER, Nicole, WAGNER, Wolfgang. Palavras-chave em contexto: análise estatística de textos. In: BAUER, Martin W. \& GASKELL, George (Orgs.), Pesquisa qualitativa com texto, imagem e som: um manual prático. Petrópolis: Vozes, 2002, p. 416-441.

LAQUEUR, Thomas. Inventando o sexo: corpo e gênero dos gregos à Freud. 1. ed. Rio de Janeiro: Relume Dumará, 2001.

MARSIAJ, Juan P. Pereira. Gays ricos e bichas pobres: desenvolvimento, desigualdade socioeconômica e homossexualidade no Brasil. Cadernos AEL, n. 10, v. 18/19, 2010, p. 131-147. Disponível em: https://www.ifch.unicamp.br/ojs/index.php/ael/article/ view/2511. Acesso em: 22 de junho de 2021.

MENANDRO, Maria Cristina Smith. Gente Jovem reunida: um estudo de representações sociais da adolescência/juventude a partir de textos jornalísticos (1968/1974 e 1996/2002). Tese (Doutorado em Psicologia). Vitória: Universidade Federal do Espírito Santo, 2004.

MISKOLCI, Richard. Pânicos morais e controle social: reflexões sobre o casamento gay. Cadernos Pagu, n. 28, v. 1, 2007, p. 101-128. Disponível em: https://www.scielo. $\mathrm{br} / \mathrm{j} / \mathrm{cpa} / \mathrm{a} / \mathrm{tWFyRWkCdWv4Tgs8Q6hps5r/?lang=pt.} \mathrm{Acesso} \mathrm{em:} 22$ de junho de 2021.

MOSCOVICI, Serge. Das representações coletivas às representações sociais: elementos para uma história. In: JODELET, Denise. As representações sociais. Rio de Janeiro: Eduerj, 2001, p. 46-65. 
MOSCOVICI, Serge. O fenômeno das representações sociais. In: MOSCOVICI, Serge. Representações Sociais: investigações em psicologia social. Petrópolis: Vozes, 2004, p. 29-110.

NOLASCO-SILVA, Leonardo \& ROSSATO, Bruno. Audiovisualidades e produção social das masculinidades: gêneros-corpos-sexualidades encenadas nos cotidianos das salas de aula. Periferia, n. 9, v. 2, jul./dez. 2017, p. 101-120. Disponível em: https:// www.e-publicacoes.uerj.br/index.php/periferia/article/view/29791. Acesso em: 22 de junho de 2021.

NORIEGA, Guillermo Nuñez. Los estudios de género de los hombres y las masculinidades: ¿ qué son y qué estudian?. Culturales, n. 4, v. 1, jan./ jun., 2016, p 9-31. Disponível em: http://www.scielo.org.mx/scielo.php?script=sci arttext\&pid=S1870-1191201600o10ooo9. Acesso em: 22 de junho de 2021.

PIMENTA, Melissa de Mattos. Masculinidades e sociabilidades: Compreendendo o envolvimento de jovens com violência e criminalidade. Dilemas. Revistas de estudos de conflito e controle social, n. 7, v. 3, jul./ago., 2014, p. 701-730, Disponível em: https:// www.lume.ufrgs.br/handle/10183/117311. Acesso em: 22 de junho de 2021.

PISCITELLI, Adriana \& SIMONI, Valerio. Masculinities in times of uncertainty and change: Introduction. Etnográfica, n. 19, v. 2, jun./2015, p. 293-299. Disponível em: https://journals.openedition.org/etnografica/4010. Acesso em: 22 de junho de 2021.

PRADO, Marco Aurélio Máximo \& MACHADO, Frederico Viana. Preconceitos contra homossexualidades: a hierarquia da invisibilidade (Preconceitos, v.5). 1. ed. São Paulo: Cortez, 2008.

REINERT, Max. Alceste, une methodologie d'analyse des donnees textuelles et une application: Aurelia de Gerard de Nerval. Bulletin de Methodologie Sociologique, n. 26, v.1, 1990, p. 24-54. Disponível em: https://journals.sagepub.com/doi/ abs/10.1177/075910639002600103. Acesso em: 22 de junho de 2021.

RIBEIRO, Aldry Sandro Monteiro. Os homossexuais em busca de visibilidade social. Tese (Doutorado em Psicologia). Brasília: Universidade de Brasília, 2005.

RODRIGUEZ, Nathian Shae, HUEMMER, Jennifer, BLUMELL, Lindsey E. Mobile masculinities: An investigation of networked masculinities in gay dating apps. Masculinities and Social Change, n. 5, v. 3, out., 2016, p. 241-267. Disponível em: https:/hipatiapress.com/hpjournals/index.php/mcs/article/view/2047. Acesso em: 22 de junho de 2021. 
ROUQUETTE, Michel-Louis. As Representações Sociais no quadro geral do pensamento social. In: MOREIRA, Antônio Silva Paredes; CAMARGO, Brigido Vizeu; JESUÍNO, Jorge Correia; NÓBREGA, Sheva Maia (Orgs.). Perspectivas teóricometodológicas em representações sociais. João Pessoa/PB: Editora Universitária, 2005, p. 189-201.

SAMPAIO, Juliana Vieira \& GERMANO, Idilva Maria Pires. " Tudo é sempre de muito!" produção de saúde entre travestis e transexuais. Estudos Feministas, n. 25, v. 2, 2017, p. 453-472. Disponível em: https://www.scielo.br/j/ref/a/ d4ghdjnqJmXq8z8hvtVcR7j/?lang=pt. Acesso em: 22 de junho de 2021

SANTOS, Luís Henrique Sacchi, \& ZAGO, Luiz Felipe. Topologias dos corpos de homens gays: deslocamentos na produção de sensibilidades biopolíticas. Nómadas, n. 39, v.1, out., 2013, p. 136-151. Disponível em: https://dialnet.unirioja.es/servlet/ articulo?codigo=4702107. Acesso em: 22 de junho de 2021.

SILVA, Alessandro Soares. \& BARBOZA, Renato. Diversidade sexual, gênero e exclusão social na produção da consciência política de travestis. Athenea digital, n. 8, v.1, out., 2005, p. 27-49. Disponível em: https://www.ssoar.info/ssoar/handle/document/6457. Acesso em: 22 de junho de 2021.

TONELI, Maria Juracy Filgueiras \& ADRIÃO, Karla Galvão. Sexualidades Masculinas: Perspectivas teórico-metodológicas. In: Grossi, Miriam. Pillar, et al. (Orgs.), Movimentos Sociais, Educação e Sexualidades. Rio de Janeiro: Garamond, 2005, p. 93106.

TONELI, Maria Juracy Filgueiras, SOUZA, Marina Gomes Coelho, \& MÜLLER, Rita de C. Flores. Masculinidades e práticas de saúde: retratos da experiência de pesquisa em Florianópolis/SC. Physis: Revista de Saúde Coletiva, Rio de Janeiro, n. 20, v.3, 2010, p. 973-994. Disponível em: https://www.scielosp.org/article/physis/2010.v2on3/973994/. Acesso em: 22 de junho de 2021.

TORO-ALFONSO, Jose. El estúdio de las homosexualidades: Revisión, retos éticos y metodológicos. Revista de Ciencias Sociales, Puerto Rico, n.14, v.1, 2005, p. 78-97. Disponível em: https://136.145.11.86/index.php/rcs/article/view/5884. Acesso em: 22 de junho de 2021.

TREVISAN, João Silvério. Devassos no paraíso: a homossexualidade no Brasil, da colônia à atualidade. 7. ed. Rio de Janeiro: Record. 2007.

Recebido em 25/03/2019.

Aceito em 04/o8/2021. 